\title{
A EFICIÊNCIA DO MARKETING NA COOPERATIVA TRITÍCOLA SEPEEENSE: UM ESTUDO DE CASO
}

\author{
ROSSÉ, Gustavo Fontinelli ${ }^{1}$ \\ OLIVEIRA, Douglas Cavalheiro de \\ TOMAZI, Marcelo \\ SCCOTT, Carla Rosane da Costa
}

ISSUE DOI: $10.3738 / 1982.2278 .1600$

\begin{abstract}
RESUMO: Este artigo tem por objetivo analisar a eficiência do marketing praticado pela Cotrisel, às vistas do composto de marketing e da exploração da marca Cotrisel. Foram analisadas proposições sobre duas perspectivas distintas: a do associado quando cliente e do associado quando fornecedor. Trata-se de uma pesquisa qualitativa, de caráter exploratório, com ênfase num estudo de caso. Na coleta de dados foram utilizadas pesquisas bibliográficas, entrevistas do tipo estruturadas, fechadas com roteiros pré-definidos, observação direta e análise documental. Ao realizar a análise dos dados utilizou-se, prioritariamente, a análise de conteúdo com o apoio de ferramentas estatísticas, visando identificar os pontos com maior percentual de concordância ou discordância e os pontos mais relevantes. Verificou-se que, no segmento arroz, a Cotrisel é amplamente eficiente e não encontra dificuldades significantes. No segmento soja, as deficiências circundam o valor pago pela oleaginosa e a relativa alta de informação sobre as vantagens que os cooperados podem obter ao negociar sua produção na cooperativa. Com relação à venda de insumos agrícolas, os cooperados esperam que a cooperativa seja mais competitiva frente aos concorrentes, fazendo jus à sua estrutura e ao poder de barganha. Fatores relacionados à prestação de assistência técnica espontânea, maior presença nas propriedades, somadas as vendas e entregas dos insumos nas lavouras surgem como necessidades que a Cotrisel não consegue atender com eficiência. Por fim, constatou-se que os cooperados consideram a credibilidade da cooperativa como fator relevante e esperam desta uma postura mais competitiva para que suas relações continuem constantes e duradouras.
\end{abstract}

Palavras-chaves: Cooperativas agropecuárias. Marketing. Cotrisel.

SUMMARY: This article aims to analyze marketing efficiency practiced by Cotrisel, the views of the marketing mix and exploitation of Cotrisel brand. Propositions were analyzed on two different perspectives: the customer when associated and associated when supplier. It is a qualitative, exploratory, focusing on a case study. In data collection were used bibliographical research, the structured type interviews, closed with predefined scripts, direct observation and document analysis. When performing data analysis was used primarily content analysis supported by statistical tools to identify the points with the highest percentage of agreement or disagreement and the most important points. It was found that, in the rice segment, is widely Cotrisel efficient and does not find significant difficulties. In the soybean segment, deficiencies surrounding the amount paid for oilseeds and relatively high information about the advantages that the cooperative can get to negotiate their production in the cooperative. Regarding the purchase of agricultural inputs, the cooperative expect the cooperative to be more competitive against competitors, living up to its structure and bargaining power. Factors related to the provision of spontaneous service, greater presence in the properties, together with the sales and delivery of inputs in crops emerge as Cotrisel needs that can't meet efficiently. Finally, it was found that the cooperative consider the cooperative's credibility as a relevant factor and expect the cooperative a more competitive posture so that your relationship can remain constant and enduring.

Keywords: Agricultural cooperatives. Marketing. Cotrisel.

\section{INTRODUÇÃO}

O cooperativismo surgiu em meados do século XIX, tendo como berço a Inglaterra e a França, com o propósito de melhorar as condições de vida da classe econômica menos favorecida. A doutrina cooperativista sofreu influências de socialistas como Owen, Fourrier, Mudie, Buchez, Blanc, Saint-Simon, Gide e outros.

${ }^{1}$ Colégio Politécnico da UFSM 
No entanto, a semente do sistema econômico do cooperativismo foi lançada em 21 de dezembro de 1844, na cidade de Rochdale, Inglaterra (OCB, 2013). Chamava-se Sociedade dos Probos Pioneiros de Rochdale. O sucesso de "Rochdale" impulsionou os movimentos cooperativistas pelo mundo a fora, contagiados pelos seus valores e princípios. Estes princípios, embora tenha sofrido pequenas alterações, são amplamente adotados pelos cooperativistas.

O cooperativismo tem representado papel cada vez mais importante no cenário atual com a expansão do agronegócio, e agora se defronta com a necessidade de mudança, de adoção de novas estratégias de gestão para poder manter-se competitivo no mercado. Ao analisar as mais diversas estratégias que a administração compreende, a administração de marketing apresenta grande relevância. Muitas decisões são tomadas e muitas conquistas são alcançadas através de decisões estratégicas de marketing. Essas decisões são gerenciadas e executadas com base nos elementos do composto de marketing, ou seja, os 4 ps: produto, preço, praça e promoção (KOTLER, 1998).

O conceito de marketing pode ser entendido como a função empresarial que cria continuamente valor para o cliente e gera vantagem competitiva duradoura para a empresa, por meio da gestão estratégica das variáveis controláveis de marketing: produto, preço, comunicação e distribuição. (DIAS, 2003, p.2)

Nas cooperativas, a prática contínua da função de marketing possibilita o crescimento sólido das receitas e das sobras, bem como a maximização da contribuição social, mas, para que isso ocorra é preciso que as funções de marketing sejam praticadas de forma eficaz e competente.

Nesse cenário, o marketing tornou-se o ponto de vista dominante no mundo dos negócios (MÖLLER, 2013). Isso se deve ao fato de que os esforços de marketing, enquanto estrutura de relacionamento, gera relações mais fortes entre clientes e vendedores que, por sua vez, melhoram o desempenho incluindo, ainda, o crescimento das vendas, participação de mercado e nos resultados (BONNEMAIZON, COVA; LOUYOT, 2007).

O tema analisado foi definido após uma entrevista prévia, aberta e semiestruturada, direcionada e aplicada aos seguintes cargos da cooperativa: vice-presidente da Cotrisel, gerente da unidade, responsável pelo departamento técnico da unidade, supervisor administrativo, supervisor do mercado agropecuário, supervisor do supermercado, todos alocados na unidade de Restinga-Sêca, acerca da percepção do marketing e da exploração da marca Cotrisel praticada atualmente.

A escolha da Cotrisel como objeto de estudo deu-se devido sua expressão no cooperativismo e no agronegócio gaúcho, estando entre as 500 maiores organizações da região sul do Brasil e entre as 100 maiores do Rio Grande do Sul, segundo a revista Amanhã (2013), e pelo destaque entres as cooperativas agropecuárias do estado. Outros fatores relevantes considerados foram sua localização e abrangência; a cooperativa está localizada na região central do estado e sediada em São Sepé, com filiais instaladas em Restinga-Sêca, Formigueiro, Vila Nova e São Pedro do Sul.

A opção de realizar o estudo na unidade Restinga-Sêca deveu-se a fatores geográficos, logísticos, e a acessibilidade e disponibilidade para realizar as entrevistas com os cooperados.

Desta forma o estudo de caso tem por objetivo analisar a eficiência do marketing praticado pela Cotrisel, às vistas do composto de marketing e da exploração da marca Cotrisel.

Com o intuito de aprofundar este estudo, procurou-se identificar a perspectiva dos associados e direção da cooperativa sobre o marketing praticado pela Cotrisel. Diante das constatações obtidas sobre as diferentes perspectivas, analisar o quão eficiente é o mix de marketing utilizado pela cooperativa. Por fim identificar os pontos ineficientes no marketing voltado para os associados, para traçar um diagnóstico com a finalidade de aprimorar as ações tanto do mix de marketing, quanto para a valorização e exploração 
da marca Cotrisel.

Nas cooperativas agropecuárias, os cooperados se deparam com a dualidade nas relações que exercem junto à cooperativa, ora são clientes ora são fornecedores. Nesta perspectiva reside um dos maiores dilemas do cooperativismo agropecuário, identificar a forma mais adequada de tratar os associados, de satisfazer a todas suas expectativas e ao mesmo tempo manter-se social e economicamente eficiente.

Atualmente as referências sobre marketing em cooperativas são restritas, e as encontradas são adaptações das teorias voltadas para organizações mercantis às cooperativas, abordando de forma segmentada as perspectivas de clientes e fornecedores. Logo, este estudo possibilitará a análise da eficiência do marketing praticado por uma cooperativa agropecuária e as especificidades advindas do duplo papel exercido pelos cooperados.

\title{
1 REFERENCIAL TEÓRICO
}

\subsection{O Cooperativismo}

O cooperativismo é um fenômeno moderno oriundo da oposição da classe operária às consequências do liberalismo econômico praticado na Inglaterra e na França do século XVIII e XIX.

A Revolução Industrial foi fator preponderante para o surgimento do cooperativismo, trazendo consigo a dicotomia entre trabalho e capital, onde ocorreu o processo de substituição do trabalho artesanal, de subsistência, para a produção industrial, carregada da ideologia capitalista de comercialização. A estratificação socioeconômica centrava-se na concentração de recursos financeiros por um grupo de indivíduos em detrimento da mão-de-obra assalariada e até mesmo marginalizada (PINHO, 1982).

No entanto, a semente do sistema econômico do cooperativismo foi lançada em 21 de dezembro de 1844, na cidade de Rochdale, Inglaterra (OCB, 2013). Chamava-se Sociedade dos Probos Pioneiros de Rochdale. O sucesso de "Rochdale" impulsionou o movimento cooperativista mundo a fora, contagiados pelos seus valores e princípios que, com pequenas alterações, são amplamente adotados pelos cooperativistas (OCB, 2013).

\begin{abstract}
As cooperativas são associações autônomas de pessoas que se unem voluntariamente e constituem uma empresa, de propriedade comum, para satisfazer aspirações econômicas, sociais e culturais. Baseiam-se em valores de ajuda mútua, solidariedade, democracia, participação e autonomia. Os valores definem as motivações mais profundas do agir cooperativo, sendo a instância inspiradora dos princípios do Movimento Cooperativista Mundial. (SCHMIDT;PERIUS 2003, apud THUSEK 2006, p. 2)
\end{abstract}

Ao longo dos anos, a economia mundial passou por profundas transformações incutidas pela globalização, pelo capitalismo e pelas rápidas transformações no campo da tecnologia e da informação, onde o livre comércio e a concorrência aberta desafiam as cooperativas a superar suas dificuldades e limitações ao passo que as pessoas estão tornando-se cada vez mais individualistas. Conforme Oliveira (2003), as vantagens competitivas das cooperativas devem estar baseadas em suas formas de interação com seus cooperados e o público geral e, não apenas, nas leis que sustentam sua constituição.

Para Boesche e Mafioletti (2006), o cooperativismo precisa ser eficiente sem perder a finalidade social em relação aos associados. As cooperativas agropecuárias deixaram de ser entidades simples e facilmente administráveis, passando a ser reconhecidas como grandes empreendimentos cooperativos. Conforme Zylbersztajn (1994), o crescimento das estruturas cooperativas é seguido pelo aumento da complexidade de sua gestão, típica de grandes corporações. 
Essa tendência vem acarretando dificuldades para as cooperativas, visto que necessitam ser organizadas e geridas de forma competente, para que possam fazer frente às outras organizações. Zylbersztajn (1994), diz que o desafio das estruturas cooperativas modernas é manter seu papel de sistema produtivo centrado no homem e, ao mesmo tempo, desenvolver organização capaz de competir com organizações de outras naturezas com orientação para o mercado.

A correlação entre a presença das cooperativas e os índices de educação e desigualdade conclui que esse tipo de organização tem um papel importante para promover a distribuição de renda na sociedade. O cooperativismo possui importância significativa na economia brasileira, sendo um sistema capaz de alinhar o desenvolvimento humano ao sustentável, devido aos seus princípios universais de origem e de evolução (MATOS;NINAUT, 2007).

\footnotetext{
Com o crescimento do sistema cooperativista é possível considerá-lo como uma ferramenta de suma importância para o aumento da econômica do país, por meio de princípios que constituem uma linha de orientação que rege o sistema e formam uma base sólida através de sua filosofia e doutrina, e é por meio dela que os cooperados levam seus valores a prática (OLIVEIRA, SILVA;SILVA, 2014, p. 4).
}

As pessoas que estão envolvidas na gestão das cooperativas sejam elas cooperados, diretores, gerentes, conselheiros, funcionários, todos, devem identificar nos conceitos de marketing ferramentas relevantes para atrair novos associados, aumentar o nível de satisfação e aumentar o volume de participação dos associados.

Atualmente as cooperativas praticam vendas sistemáticas e organizadas, onde os principais pontos são agrupados e coordenados. O foco das vendas é a troca de um produto ou serviço por outro - dinheiro, enquanto o marketing busca a satisfação das necessidades das pessoas através do processo de troca.

Dessa forma, observa-se que o marketing obriga a cooperativa a mostrar à sociedade o que está fazendo, onde pretende chegar, que públicos pretende atender, quais os desejos e necessidades serão atendidos, que melhorias serão implementadas, qual será a eficácia dos serviços. Para Abreu (2000), algumas ações específicas voltadas para os cooperados devem ser implementadas pelas cooperativas, a fim de atender às suas exigências enquanto consumidor e fornecedor.

\subsection{O Marketing nas cooperativas}

O cooperativismo brasileiro vem passando por grandes transformações, influenciado pelo impressionante crescimento do agronegócio, que por sua vez também passa por transformações advindas da Revolução Verde.

Segundo Kotler (1994) o marketing é a administração eficaz que uma instituição adota em suas relações com vários públicos e mercados. Para Dias (2003) a administração de marketing é um conceito que resume a função do marketing, ou seja, é o processo de planejamento, execução e controle das estratégias de táticas de marketing, visando otimizar os resultados tanto para os clientes quanto para os stakeholders.

As cooperativas estão percebendo a necessidade de tornar públicas suas qualidades, para tanto, estão maximizando a importância do marketing investindo em novas estratégias de comunicação e de marketing propriamente dito.

Os últimos acontecimentos de ordem econômica, política e social têm exercido maiores cobranças das organizações no sentido de otimização dos processos de gestão. Em virtude disto, a aplicação de uma profunda análise do ambiente de marketing possui uma relevância ainda maior nas rotinas administrativas das organizações (SCHERER, et al, 2015). 
Administração de marketing em cooperativas é um conjunto de ações que envolvem planejamento, organização, direção e controle da área comercial de um estabelecimento, seja empresa privada ou cooperativa. Um bom planejamento de marketing minimiza os erros, que podem colocar a empresa em situação desfavorável, aperfeiçoa recursos e coloca a empresa à frente da concorrência; cria diferencial competitivo e agrega valor à sua marca; aumenta a lucratividade através de bons negócios e conquista a cada dia novos clientes (REIS et al, 2012).

A imagem da empresa, de seus produtos e serviços, são fatores que influenciam na decisão de compra de seus clientes. Partindo desta ideia muitas organizações realizam investimentos para projetar sua imagem, como propaganda e relações públicas, visando criar uma atmosfera favorável de credibilidade e preferência. Dias (2003) define estas ações como marketing institucional, que são ações de marketing direcionadas para a criação de imagem favorável e preferência para determinada organização ou empresa.

O marketing é um processo social e gerencial através do qual os indivíduos satisfazem suas necessidades e desejos através da troca de produtos de valor por outros. Ao mesmo tempo é uma ferramenta imprescindível para fortalecer a imagem da cooperativa, seus negócios e seus laços com cooperados e clientes.

Nas cooperativas, a prática contínua da função de marketing possibilita o crescimento sólido das receitas e das sobras, bem como a maximização da contribuição social, mas, para que isso ocorra é preciso que as funções de marketing sejam praticadas de forma eficaz.

O marketing, na perspectiva de função empresarial, integra um conjunto de funções que gerenciam recursos e geram resultados agregando valor econômico ao processo empresarial como um todo. As decisões específicas da função de marketing que compõem o mix de marketing referem-se a quatro variáveis: produto, preço, promoção e praça ou distribuição. A figura 1, a seguir, representa o que compreende o mix de marketing.

Figura 1: O conceito de marketing

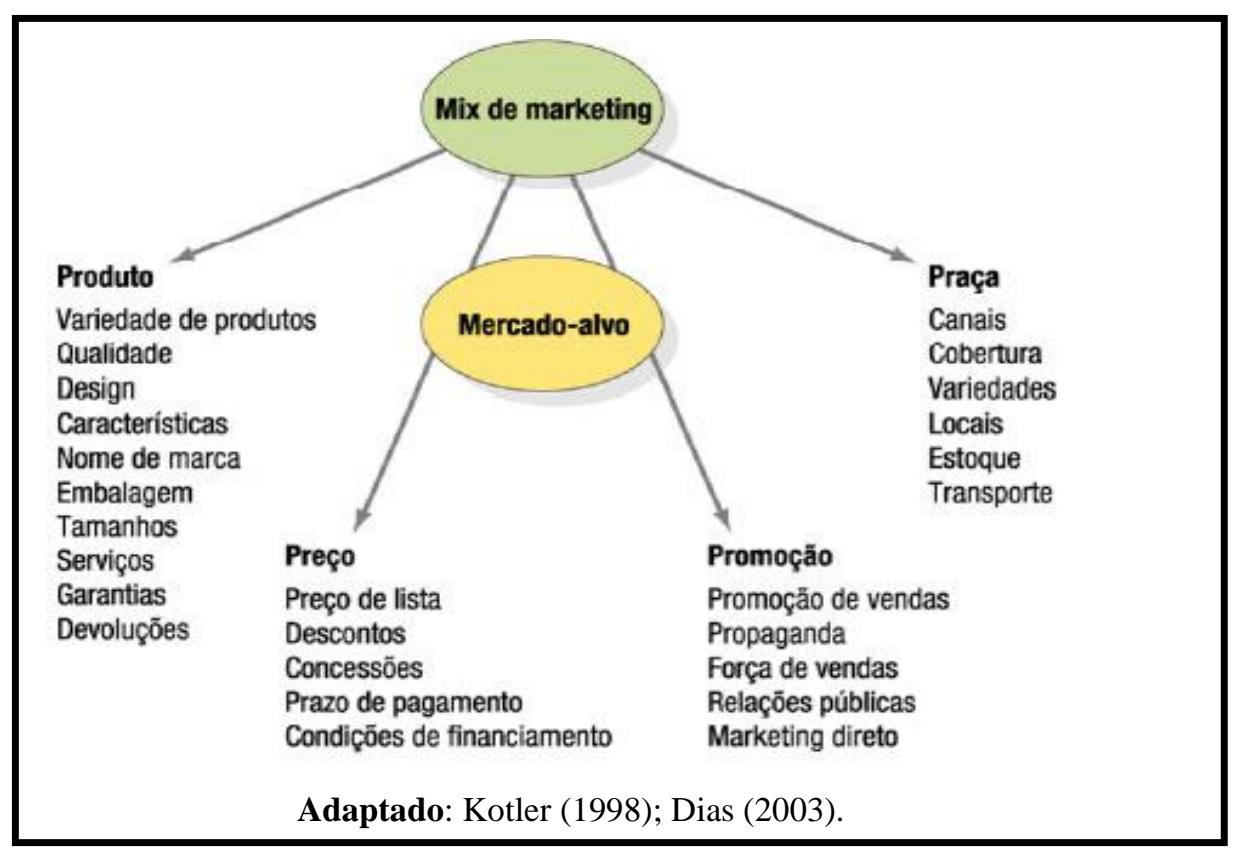

Segundo Cobra (2003) as decisões de produto englobam a identificação de oportunidades de lançamento de produtos e serviços, a adequação destes às necessidades e desejos dos clientes, a formulação das estratégias de produtos e linhas de produtos, como a diferencia e posicionamento por exemplo. 
As decisões de preço são consideradas por Kotler (1998), as que envolvem a seleção da estratégia de preço que gere vantagem competitiva e diferenciação para cada produto, podendo assim maximizar o retorno para a empresa e para os parceiros.

As decisões de promoção são aquelas relativas aos investimentos em estratégias e atividades de comunicação, como propaganda, marketing direto, relações públicas, publicidade, eventos e seminários, e também na promoção de vendas através de sorteios, prêmios ao consumidor, descontos de preços e brindes, dentre outros (CHURCHILL;PETER, 2000).

Já a variável distribuição é descrita por Dias (2003) como a escolha dos canais de vendas e distribuição para que o produto esteja no lugar certo, no momento certo e o cliente possa efetuar a compra e satisfazer suas necessidades.

Conforme Faria (2010) o marketing é um instrumento valioso para responder às tendências percebidas de mudanças nos negócios agropecuários. As cooperativas agropecuárias precisam ter foco estratégico sobre o mercado, produto, distribuição e promoção, garantindo sua presença efetiva no agronegócio brasileiro.

A aplicação de estratégias de marketing adequadas para a cooperativa é essencial para manter a competitividade no mercado em que está inserida. A cooperativa pode apresentar vantagens competitivas em relação a seus concorrentes, tendo em vista sua relação privilegiada com seus cooperados, mas ao mesmo tempo não pode descuidar-se dos demais clientes, e dar a devida importância ao mercado, pois esta é uma das melhores táticas para manter-se ativo.

O marketing na cooperativa é um instrumento indispensável para fortalecer sua imagem, além de ser um mecanismo de distribuição de seus negócios para si própria. Para que isso ocorra, a cooperativa deve estar em sintonia total com seus cooperados, associados, toda sua equipe de funcionários e com a disponibilidade dos melhores serviços (REIS, et al, 2012).

O planejamento de marketing, dentro do cooperativismo, tendencia a cooperativa a promover a satisfação de seus cooperados e clientes, proporcionando seu crescimento global. A satisfação das necessidades é atingida quando o resultado do desempenho do produto ou serviço se iguala à expectativa do cliente ou a supera (CHURCHILL;PETER, 2000).

Conforme Oliveira (2003), inúmeras são as vantagens proporcionadas pelo planejamento de marketing dentro do cooperativismo, sendo algumas delas: direcionamento de esforços para os resultados comuns. Os objetivos e as metas são estabelecidos por todos executivos e profissionais da cooperativa; aprimoramento do seu modelo de gestão; estruturação das cooperativas para a otimizada busca de inovação e novos conhecimentos; aprimoramento de seu sistema orçamentário; maior facilidade no estabelecimento e no acompanhamento e avaliação de indicadores de desempenho; consolidação de serviços mais estruturados ao sistema cooperativista, através da interação entre as diversas instituições do sistema (OCB, OCEs, Federações, Centrais e Cooperativas) são mais delineadas para a busca de resultados comuns.

Por fim, muitas organizações atribuem ao marketing a função de otimizar a atração de clientes e consequente ingresso de novas receitas. As cooperativas, na maioria das vezes, só reconhecem o valor do planejamento formal quando encontra dificuldades com suas receitas. Elas deveriam estar orientadas estrategicamente para o planejamento em longo prazo, norteado pela missão da cooperativa, ciente de seus recursos, da sua situação econômico-financeira e amparado pela analise sistemática do ambiente para poder determinar suas prioridades e estratégias adequadas. 


\section{ASPECTOS METODOLÓGICOS}

Do ponto de vista metodológico, esta pesquisa envolveu um grande número de relações, significados, processos e valores, que demandaram uma contextualização para seu melhor entendimento. Devido à sua complexidade foi classificada como qualitativa. Todavia neste estudo em alguns momentos, foi necessário recorrer a variáveis numéricas e quantificáveis, analisar dados tabulados e determinar a dimensão mais precisa das informações, definindo-se então o caráter quantitativo da pesquisa.

Quanto aos objetivos, este estudo é de caráter exploratório, tendo por objetivo tornar explícitas as ações de marketing da Cotrisel. A pesquisa baseou-se em levantamentos bibliográficos e entrevistas com associados, diretores e gestores da cooperativa a fim de proporcionar maior nível de compreensão sobre o problema de pesquisa.

Além disso, para que esta pesquisa pudesse ser realizada, adotou-se como desenho de pesquisa o estudo de caso. O estudo é considerado de caso, uma vez que centrou-se em alcançar uma explicação para os fatos observados, a partir da análise da eficiência do marketing praticado pela Cotrisel.

Ao longo do desenvolvimento da pesquisa, procurou-se realizar um estudo profundo dos dados, a fim de permitir o amplo conhecimento sobre o marketing em cooperativas agropecuárias e analisar a eficiência do marketing praticado pela Cotrisel. Para tanto foram utilizados os seguintes instrumentos para a coleta de dados: pesquisa bibliográfica, entrevistas estruturadas, fechadas e com roteiros previamente definidos, observação direta e análise documental.

A pesquisa bibliográfica foi direcionada para obtenção de informações a respeito do cooperativismo, da gestão de cooperativas e do marketing nas cooperativas.

Em se tratando das entrevistas, estas foram construídas com base num conjunto de categorias de análise delineadas a partir das temáticas expostas no referencial teórico deste artigo. Estas entrevistas foram realizadas junto aos cooperados, sendo compostas por proposições fechadas, com cinco opções de resposta - concordo plenamente, concordo parcialmente, sem opinião, discordo parcialmente e discordo totalmente - e por fim uma questão aberta compreendendo uma percepção geral sobre o marketing da Cotrisel.

Quanto aos entrevistados, a amostragem foi definida e composta apenas por cooperados produtores rurais, proprietários ou arrendatários de propriedades no município de Restinga-Sêca, e que depositam sua produção agrícola de arroz e/ou soja na Cotrisel durante safra 2013/2014. Considerou-se também a acessibilidade e a disponibilidade dos cooperados, entrevistando-se apenas os indivíduos que estiveram na cooperativa no período compreendido entre 01 e 30 de novembro de 2014 . No total foram realizadas 30 entrevistas.

$\mathrm{Na}$ análise documental, buscaram-se informações acerca da definição do perfil econômico-social da Cotrisel, através da analise das demonstrações contábeis e relatório da diretoria com base no exercício social 2013, reportagens em revistas e mídia digital. A saber, foram acessados os seguintes documentos: relatórios institucionais, manual de planejamento estratégico, atas de assembleias e de reuniões, organograma institucional, manuais de procedimentos administrativos, rotinas de trabalho, rotinas e procedimentos de treinamento, dentre outros.

A observação direta realizou-se na unidade da Cotrisel em Restinga-Sêca, onde se observou a relação do cooperado com a cooperativa, procurando identificar e perceber a influência do marketing nas relações cotidianas entre as partes. A observação direta foi efetivada por meio de observação de reuniões internas da presidência, direção e de coordenação, de reuniões com cooperados, assembleias gerais, de procedimentos de rotinas de trabalho administrativo, de treinamentos com equipes de trabalho, de reuniões de avaliação do trabalho, dentre outros. 
A partir disso, foram realizadas as análises descritivas e o confronto teórico. Para tanto, procedeuse a análise das informações qualitativas, que foi feita sob a ótica da análise de conteúdo e ao longo do processo de discussão dos resultados.

Para que essa análise de conteúdo pudesse ser realizada, tomaram-se como referência os seguintes passos: a) pré-análise, cujo objetivo foi sistematizar as ideias iniciais obtidas por uma estrutura teórica definida e apontar os indicadores para a interpretação das informações obtidas. Nessa fase dedicou-se a uma leitura geral do material eleito para a análise, no caso o produto das entrevistas, que serão apresentados na análise dos resultados; b) exploração do material, que teve como propósito a construção das operações de codificação, considerando-se os recortes dos textos em unidades de registros, a definição de regras de contagem e a classificação e agregação das informações em categorias simbólicas ou temáticas; c) tratamento dos resultados, inferência e interpretação, que consistiu em captar os conteúdos manifestos e latentes contidos em todo o material coletado. Tal procedimento foi realizado através da justaposição das diversas categorias existentes em cada análise, ressaltando os aspectos considerados semelhantes e os que foram concebidos como diferentes.

Cabe salientar que esse trabalho foi realizado de forma categorizada, sem a necessidade do uso de software específico.

$\mathrm{Na}$ análise dos dados utilizou-se a análise estatística, podendo assim identificar os pontos com maior percentual de concordância ou discordância, os pontos mais relevantes e analisá-los de maneira que possibilitasse verificar a eficiência do marketing praticado pela cooperativa.

Dessa forma, entendeu-se que as correlações entre as categorias permitiram promover informações complementares sobre diferentes aspectos estudados quanto à eficiência do marketing na Cotrisel. Foi com base nessas contribuições que se pode promover de modo efetivo o arcabouço necessário para atender aos objetivos da pesquisa e que ofereceu ainda condições de produzir instrumentos complementares para um melhor desempenho da ação extensionista em todas as suas concepções.

\section{ANÁLISE DOS RESULTADOS}

A Cooperativa Tritícola Sepeense - COTRISEL está sediada São Sepé e possui unidades em Restinga-Sêca, Formigueiro, Vila Nova do Sul e São Pedro do Sul, com estruturas próprias de recebimento, secagem e armazenagem de cereais, representada por um complexo de 8 (oito) unidades com armazéns e lojas de insumos, 3 (três) indústrias de beneficiamento de arroz, 1 (uma) fábrica de rações, uma rede de 10 (dez) lojas de varejo, sendo 4 (quatro) lojas de supermercados e 5 (cinco) lojas de mercado agropecuário e 1 (um) posto de combustíveis.

Conta com a participação de 4.983 associados e um quadro funcional composto por 800 colaboradores. Em 2013 a Cotrisel obteve um faturamento bruto superior a R \$312.000.000,00.

Hoje, tem no arroz irrigado o carro chefe de seus produtos sem descuidar do recebimento de soja, trigo, sorgo, milho e feijão, produtos de grande importância econômica. Depois de beneficiado, o arroz é comercializado, com marca própria nos estados de Espírito Santo, Rio de Janeiro, Minas Gerais e Bahia, em 2012 foram comercializados aproximadamente 2.560 fardos de arroz, fazendo da SEPÉ uma das mais consumidas no país.

Em Restinga-Sêca, a Cotrisel possui um complexo composto por uma unidade de recebimento de grãos, setor administrativo e departamento técnico, e duas lojas de varejo, sendo um supermercado e um mercado agropecuário, contando com um quadro funcional de 118 colaboradores, alocados da seguinte forma: 
O quadro social da Cotrisel em Restinga-Sêca é composto por 1.300 associados, entretanto, apenas 538 destes associados realizaram depósitos de sua produção na Cotrisel, os demais, 762 associados foram considerados inativos. Logo, a quantidade de associados ativos corresponde à 41,38\% do total de associados da unidade. Dentre os associados ativos, 150 depositaram somente arroz, 168 depositaram somente soja e 220 depositaram arroz e soja na cooperativa.

\subsection{O marketing na Cotrisel}

De modo a permitir uma análise mais apurada a respeito da eficiência do marketing na Cotrisel, entendeu-se que era fundamental orientar o instrumento de coleta para que pudesse oferecer respostas suficientes a respeito das questões que envolvem produto, preço, praça e promoção. Assim, esses itens serão analisados a partir de agora.

O primeiro item analisado versou sobre a questão do produto. Dessa forma, considerou-se relevante analisar o produto sob a ótica do seu mix, da sua qualidade, da relação com as tendências do mercado, quanto às tecnologias, sobre o valor agregado dos produtos, bem como sobre a questão da credibilidade e da transparência da cooperativa.

Quando analisada a questão do mix de produtos, foi possível observar, através do instrumento de pesquisa, que o mix de produtos oferecidos pela cooperativa atende satisfatoriamente as necessidades dos associados, tendo a concordância de $96,67 \%$ dos associados.

Quanto à qualidade dos produtos, $100 \%$ dos entrevistados concordaram plena ou parcialmente que os defensivos agrícolas e os fertilizantes são de boa qualidade e atendem satisfatoriamente às suas necessidades. Já quanto às sementes, não se verificou a soberana concordância da proposição anterior, sendo que $46,67 \%$ dos associados afirmaram que as sementes são de boa qualidade e atendem satisfatoriamente suas necessidades, $40 \%$ concordaram parcialmente e 13,33\% discordaram parcialmente.

Conforme comentários realizados durante a entrevista foi possível identificar que a insatisfação com as sementes está ligada a questões técnicas, como uniformidade das sementes e padrão de germinação. Todavia os associados ainda alegaram que nas duas últimas safras o padrão das sementes melhorou sensivelmente.

Ao longo do processo de investigação, foi constatado que a qualidade dos produtos apresenta grande relevância na decisão de compra dos insumos, visto que $96,67 \%$ dos entrevistados concordaram plena ou parcialmente que a esta variável tem influência em suas decisões de compra. Segundo as ponderações de um dos entrevistados, "é preferível pagar um pouco mais caro pelos produtos oferecidos pela cooperativa e ter a certeza de que o resultado da utilização do produto será o melhor possível".

Nesta proposição também foi possível identificar através dos comentários que a credibilidade da cooperativa apresenta grande influência sobre a decisão de compra dos insumos, ao passo que o nível de confiança depositado na cooperativa é superior ao creditado aos concorrentes.

Ainda dentro da análise do fator qualidade do produto, quando questionados sobre a qualidade da assistência técnica da cooperativa e seu auxílio na gestão das propriedades, 93,34\% dos entrevistados concordaram plenamente ou parcialmente com a qualidade do serviço prestado, 3,33\% não opinaram e $3,33 \%$ discordaram totalmente. Porém, ao mesmo tempo em que a grande maioria dos associados reconhece a qualidade do serviço prestado, sentem falta de um número maior de engenheiros agrícolas para que as visitas nas propriedades ocorram de forma espontânea, deixando de ser prestada mediante chamados.

Conforme um dos entrevistados, 
[...] a assistência técnica da Cotrisel é ótima, me auxilia muito quando tenho que comprar os insumos para a lavoura, mas eu acho que tinha que ter mais um agrônomo para sair a campo, para ir ver a minha lavoura sem eu precisar chamar, o serviço prestado pelos engenheiros é bom, mas eles já não conseguem atender a todos, é muita gente e eles são só os dois e um deles tem que ficar no escritório para o outro sair.

$\mathrm{Na}$ proposição em que o questionamento procurou identificar a influência da utilização da assistência técnica da cooperativa na decisão do associado sobre a compra dos insumos agrícolas, $80 \%$ concordaram plena ou parcialmente e $20 \%$ discordaram parcial ou plenamente.

Um dos entrevistados que discordaram totalmente alegou que,

[...] eu procuro o engenheiro da cooperativa para trocar uma ideia, os guris já conhecem a minha lavoura, mas nem sempre eu compro os produtos aqui, às vezes não tem o produto que eu quero, outras vezes o preço do mesmo produto no concorrente é melhor, e aí fica difícil negociar sempre com a Cotrisel.

$\mathrm{Na}$ afirmativa que considera a assistência técnica da cooperativa como um diferencial frente às outras organizações, apenas $53,33 \%$ dos entrevistados concordaram plenamente, $20 \%$ concordaram parcialmente, 3,33\% não opinaram, 20\% discordaram parcialmente e 3,33\% discordaram totalmente. Para alguns associados, tanto os que apresentaram um nível de concordância parcial quanto os que discordaram parcial ou plenamente, a assistência técnica já não é mais o grande diferencial da cooperativa como no passado. Eles alegam que os concorrentes também estão oferecendo assistência aos produtores, porém a diferença é que o departamento técnico da cooperativa não tem o perfil de incentivar a compra de produtos desnecessários ou ineficientes em determinadas situações.

$\mathrm{Na}$ opinião de um dos entrevistados, "hoje em dia praticamente todo mundo da assistência nas lavouras, se não o pessoal não compra, por isso eu acho que isso já não é mais um grande diferencial. Outro entrevistado apontou que "a vantagem da cooperativa é que o pessoal não é vendedor, não ficam tentando empurrar produto que não funciona". Novamente a credibilidade da cooperativa aparece como ponto influenciador nas relações negociais.

No questionamento sobre a cooperativa acompanhar as tendências do mercado e a busca constante por novos produtos a fim de qualificar o mix de insumos, 50\% dos entrevistados concordaram plenamente, $36,67 \%$ concordaram parcialmente e 13,33\% dos associados discordaram parcialmente. As ponderações feitas pelos associados indicaram que a cooperativa demora a apresentar novos produtos, ao passo que os concorrentes apresentam os produtos novos com relativa antecedência.

Ao analisar a receptividade às novas tecnologias, $60 \%$ dos participantes concordaram plenamente que a cooperativa é receptiva, 26,67\% concordaram parcialmente, 3,33\% optaram por não opinar e $10 \%$ discordaram parcialmente. Nesta proposição os comentários negativos também circundaram a morosidade da cooperativa para aderir às novidades tecnológicas e apresenta-las aos associados.

Quando questionados sobre a percepção do valor agregado aos produtos como um diferencial da cooperativa, 56,67\% dos entrevistados concordaram plenamente com a afirmação, 26,67\% concordaram parcialmente, $13,33 \%$ não opinaram e apenas 3,33\% discordaram parcialmente. A questão estrutural disponibilidade de insumos em estoque, ambiente de atendimento climatizado e departamento técnico dentre outros - teve um número expressivo de citações entre os associados que concordaram de alguma forma.

Para um dos entrevistados,

[...] é difícil encontrar nos concorrentes uma estrutura parecida com a que a Cotrisel oferece, a gente chega aqui e é bem atendido, tem o ar-condicionado no verão, o 
cafezinho, a água gelada, tem os agrônomos para atender a gente, tem os insumos ali no galpão, dá para levar quando quiser e q quantidade de produto que quiser para mim isso é importante.

Outro entrevistado assinalou que,

[...] nós, associados precisamos reconhecer essas coisas, porque todo mundo gosta mas poucos valorizam. Tem uns concorrentes que às vezes não tem nem um banco para o cara sentar, que dirá um copo de água gelada, isso quando não atendem mal a gente. Aqui o negócio é diferente.

A proposição que analisou a influência da credibilidade e transparência da cooperativa quanto à seus processos na decisão de onde depositar sua produção, 83,33\% dos associados concordaram plenamente e 6,67\% concordaram parcialmente. A credibilidade da cooperativa foi citada em inúmeros comentários, sendo que alguns deles foram citados em proposições anteriores. Esta credibilidade atribuída a Cotrisel por seus cooperados pode ser considerada um dos pontos mais forte da cooperativa, sendo sua influência positiva é perceptível em praticamente todas as relações entre cooperado e Cotrisel. A transparência apresenta sua relevância na relação de confiança estabelecida entre as partes, possibilitando ao associado esclarecer qualquer duvida da forma mais clara e objetiva possível.

Essa situação comprova-se a partir dos comentários realizados pelos associados, e em especial por um dos entrevistados, que apontou que,

[...] aqui na Cotrisel a gente consegue saber tudo o que acontece desde que o produto chega na cooperativa até a hora de vender, é tudo muito claro e bem explicado, já cheguei aqui com duvidas mas sempre sai sem nenhuma, na Cotrisel não fica nada escondido nas entrelinhas, entende! Tudo o que precisar para comprovar o que foi feito a cooperativa apresenta, têm os tickets, os extratos, em fim, tudo o que eu fizer aqui dentro fica no papel, e isso é muito importante.

O item que analisou a comercialização dos produtos é realizada de forma clara e satisfatória, 93,33\% dos respondentes concordou plena ou parcialmente com a afirmativa. O percentual de concordância aferido vai ao encontro do resultado do item acima, onde a importância da credibilidade e da transparência fica evidenciada.

Quando analisada a credibilidade da cooperativa quanto ao pagamento pelos grãos comercializados e sua influência na decisão de depositar a produção, $90 \%$ dos entrevistados concordaram plena ou parcialmente, 3,33\% não opinaram e 6,67\% discordaram totalmente. Falar em credibilidade torna-se repetitivo, mas sua relevância é incontestável e, quando relacionada a fatores financeiros sua importância é maximizada.

Alguns dos entrevistados relataram em suas observações que a certeza de receber em dia, nos prazos pré-estabelecidos, fortalecem sua relação com a cooperativa, e um deles atestou que

[...] para mim o importante é saber que eu vou receber certinho, no dia combinado. A gente sempre tem os compromissos, tem que pagar o banco, tem que pagar as contas e vendendo aqui na cooperativa a gente fica tranquilo porque sabe que sempre da tudo certo. A primeira coisa é honrar com os compromissos, o resto vem depois.

Já outros encaram essa situação de forma normal e veem o pagamento como uma consequência das negociações, mas ainda assim depositam um volume maior de confiança na Cotrisel. Na opinião de um dos entrevistados, 
[...] hoje em dia todo mundo paga direitinho, sabem que se agirem de má fé vão perder um cliente, mas a gente conhece o histórico da cooperativa e sabe que pode confiar sempre, é uma empresa grande e acho que nunca deixou de honrar com seus compromissos com os associados.

Partindo para a análise das proposições acerca do item preço, inicialmente foi observada o perspectiva de cliente, analisando-se os preços dos insumos agrícolas.

$\mathrm{Na}$ afirmativa que considera a competitividade dos preços da cooperativa, apenas $10 \%$ dos entrevistados concordaram plenamente, 56,67\% concordaram parcialmente. Outros 30\% discordaram parcialmente e 3,33\% discordaram totalmente com a afirmação. Verifica-se que o maior percentual das respostas concentrou-se nas parcialidades, tanto de concordância quanto de discordância, 88\%, assim é possível ponderar que a Cotrisel apresenta fragilidades com relação aos preços dos insumos.

Os comentários dos associados evidenciam que em grande parte das ocasiões a cooperativa não apresenta o melhor perco do mercado, e que não é este o principal fator que os leva a comprar seus insumos na cooperativa, sendo que um deles apontou que,

[...] os preços da cooperativa estão na média do mercado, não fica nem muito mais barato nem muito mais caro, mas muitas vezes até é mais caro, mas por outro lado a gente sabe que os produtos são de boa qualidade, e também reconhece a estrutura da cooperativa junto a esses preços, no fim sai uma coisa pela outra".

Pode-se considerar uma situação normal a cooperativa não oferecer sempre os melhores preços do mercado, a medida que este mercado é a cada dia mais competitivo e a cooperativa sofre com o ônus de ser referencia para os concorrentes, sendo atacada por todos em seus respectivos segmentos.

Boa parte dos produtores é imediatista, e procuram resultados em curto prazo e vislumbram ganhos imediatos em todas as negociações realizadas, buscando sempre os melhores preços do mercado. Essa visão individualista dos produtores tem dificultado as negociações entre cooperativa e cooperados, visto que a flexibilidade de negociação da cooperativa é limitada, em virtude da adoção dos princípios de igualdade cooperativismo que são respeitados pela Cotrisel.

Os grandes produtores buscam melhores preços através do seu volume de compra, e do poder de barganha que apresentam, tendo como argumento o ganho em escala. Um entrevistado assinalou que, "eu compro apenas uma pequena parte dos insumos aqui na cooperativa, é difícil a negociação, na maioria das vezes os concorrentes batem os preços da cooperativa nas negociações". Isso permite inferir que situações como essa possibilitam a percepção que a cooperativa tem muito a crescer em vendas, desde que se trabalhe de forma adequada as condições do mercado.

Os pequenos produtores, por sua vez, procuram otimizar a utilização dos recursos financeiros, devido suas limitações toda a economia realizada, por menor que seja, representa uma parcela interessante no final da safra. Um dos respondentes relata que, "a gente que tem poucos recursos, pouco dinheiro, tem que comprar onde é mais barato". Assim a questão apresenta sua relevância.

Ao analisar se os preços dos produtos são o diferencial no momento de decisão de compra dos insumos $80 \%$ dos entrevistados concordou plena ou parcialmente, 3,33\% não opinaram e 16, $67 \%$ discordaram parcialmente. Foi possível observar que, o preço é relevante, mas existem outros fatores que influenciam tanto quanto os preços, como a credibilidade e idoneidade da cooperativa ao vender produtos de qualidade que possuem eficiência comprovada e geralmente testada antes de serem apresentados aos produtores, soma-se a estes fatores a assistência técnica prestada pela cooperativa que por sua vez fortalece mais ainda mais a intenção do produtor em negociar seus insumos com a cooperativa. 
Os preços, como diferencial no momento de decisão de compra também sofrem influência da cultura imediatista dos cooperados, alguns deixam de comprar da cooperativa por questões de centavos. Embora exista esta tendência imediatista, para a maioria dos entrevistados somente as grandes diferenças de preço são realmente relevantes, quando os valores são equivalentes ou com pouca variação para mais ou para menos a tendência é comprar da cooperativa por razões elencadas anteriormente.

As formas de pagamento e a concessão de credito por parte de cooperativa obtiveram 83,33\% e $73,33 \%$ de concordância plena ou parcial respectivamente. Contudo os associados consideram que a importância destas duas afirmativas fica minimizada ao passo que o mercado em geral oferece as mesmas condições de pagamento.

As formas de financiamento apresentaram um percentual menor de concordância, sendo $30 \%$ plenamente, 36,67\% parcialmente, 3,33\% sem opinião, 20\% discordaram parcialmente e $10 \%$ discordaram totalmente. Segundo os relatos dos entrevistados foi possível perceber que as formas de financiamento são mais importantes para os pequenos produtores, podendo considerar a dependência da cooperativa por alguns cooperados.

Num desses relatos observou-se que,

[...] o financiamento da cooperativa é de extrema importância para mim, os recursos que o banco me oferece são insuficientes para eu fazer a lavoura, se não fosse a cooperativa me financiar ficaria difícil de plantar. Os prazos para pagar na safra facilitam bastante também, chega uma época do ano, principalmente antes de começar a colher que a gente não tem mais dinheiro para comprar as coisas à vista, nesse sentindo a cooperativa ajuda bastante.

Os grandes produtores dão menor importância às formas de financiamento, ao passo que possuem uma estrutura financeira mais sólida. Para um desses entrevistados,

[...] eu não dependo do financiamento da cooperativa para plantar, sempre financio uma parte no banco, mais como garantia, e a outra parte faço com recursos próprios, esporadicamente compro com prazo safra, mas é mais for comodidade, para não precisar andar com cheque ou dinheiro na lavoura mesmo.

Com relação à flexibilidade nas negociações de insumos e possíveis vantagens frente aos concorrentes, as respostas foram divididas, apenas $20 \%$ concordaram plenamente, $26,67 \%$ concordaram parcialmente, 3,33\% não opinaram, 33,33\% discordaram parcialmente e 16,67\% discordaram totalmente. A cooperativa não possui mesma postura de negócios voltada para vendas que as organizações particulares, ao passo que carrega consigo o princípio de igualdade entre os sócios, e assim não é prática a concessão de exceções. Todavia alguns associados conseguem obter algumas pequenas vantagens em suas negociações com a cooperativa, mas não caracteriza uma vantagem frente aos concorrentes, as percepções são diferentes para os pequenos e para os grandes produtos.

Os pequenos produtores, em sua maioria, percebem apenas a flexibilidade nos prazos de pagamento. Para um dos entrevistados, "é difícil negociar com a cooperativa, eu pelo menos nunca consegui ganhar nada em relação a preços, é sempre o preço do dia, que eu acho que é para todo mundo o mesmo". Para outro entrevistado, "tem os descontos do cartão plus ${ }^{2}$, mas o que a gente consegue é negociar são os prazos, de resto é complicado".

Os grandes produtores também consideram a cooperativa pouco flexível, e não consideram este ponto como uma vantagem oferecida pela cooperativa. Na opinião de um entrevistado, "eu considero a

${ }^{2}$ Cartão concedido ao associado que deposita toda produção na cooperativa 
negociação com a cooperativa complicada, quando a tem preço bom esse preço é para todos, não existe diferenciação". Conforme outro entrevistado, "em algumas situações a gente até tenta comprar aqui, mas os preços não mudam, eu já consegui barganhar algum frete, um prazo diferenciado, mas preço mesmo nunca". Para outro entrevistado, "isso a cooperativa poderia mudar, seria uma oportunidade de aumentar o volume de negócios, comigo com certeza, mas acho que se aplica a outros associados".

A partir de agora serão analisadas proposições abrangendo a temática praça na perspectiva dos associados quando clientes da cooperativa.

Quando analisada a entrega dos insumos na propriedade como um fator de influência na decisão de compra, 50\% dos associados concordaram plenamente, afirmando a importância, 23,33\% concordaram parcialmente, 3,33\% não opinaram, 10\% discordaram parcialmente e 13,33\% discordaram totalmente. A cooperativa não possui a pratica de entrega de insumos nas propriedades sem custos para os associados. Em situações especificas, quando o volume de compra atinge o peso de uma carga fechada as entregas são feitas diretamente na propriedade do associado sem passar pelos galpões da cooperativa. É uma situação que favorece ambas as partes, evita o retrabalho (descarregar e carregar novamente) e otimiza a ocupação dos espaços, já para o associado representa a economia do frete e a disponibilidade imediata do produto adquirido.

Nos últimos anos a cooperativa adotou um sistema de entrega programada, onde o associado liga para a cooperativa e agenda o seu frete. Este frete é realizado por terceiros previamente acertados com a cooperativa a um valor fixo por tonelada. $\mathrm{O}$ entregador por sua vez tem a obrigação de realizar descarga da forma que o associado julgar conveniente, sem que ele tenha a necessidade de auxiliar na descarga. Esta pratica vêm tendo boa aceitação, tanto pela facilidade quanto pela comodidade de receber os produtos sem precisar fazer esforço físico.

Contudo, por ser um serviço pago, o associado não considera que este seja um fator relevante na decisão de compra, ou seja, não é apenas esse serviço que os levam a comprar na Cotrisel.

Para um dos entrevistados, "é uma facilidade para mim, se eu fosse vir buscar aqui eu ia gastar combustível e ainda teria que descarregar em casa, seria melhor ainda se não tivesse custo para mim".

Para outro entrevistado,

[...] eu nunca utilizei este serviço, mas já recebi adubo da cooperativa direto no meu galpão, é bom, me economiza tempo e o custo do frete, mas não me influencia muito não, as propostas dos concorrentes são bem parecidas com as da cooperativa e eles também entregam em casa, o que falta mesmo para a cooperativa é entregar os venenos na lavoura, às vezes a gente está no meio de uma aplicação e tem que para tudo para vim aqui buscar um produto, tinha que facilitar um pouco mais a vida do produtor e entregar como os outros fazem.

A cooperativa encontra dificuldades na distribuição de seus produtos, principalmente nos defensivos agrícolas. O departamento técnico da cooperativa, até um passado próximo não era orientado para a venda de insumos agrícolas, mas sim para a assistência técnica literalmente, o objetivo era atender ao associado e lhe indicar produtos que poderiam solucionar seus problemas, deixando livre para comprar tais produtos onde ele considerasse mais conveniente.

É possível perceber que, embora a cooperativa não atenda plenamente às expectativas dos associados quanto a sua presença e as suas formas de distribuição, ela apresenta uma crescente evolução nas vendas de insumos agrícolas, e analisando todo este contexto cabe relatar que a Cotrisel reconhece as necessidades dos associados, mas não consegue atende-las de forma adequada deixando os concorrentes ocupar estas lacunas. 
Para $86,67 \%$ dos entrevistados concordaram plena ou parcialmente que a presença do departamento técnico da cooperativa nas suas propriedades os influencia a comprar os insumos na Cotrisel. Muitos associados consideram fundamental para os seus empreendimentos rurais a assistência prestada pela cooperativa, a troca de ideias e de conhecimentos que ocorrem durante os atendimentos.

Na opinião de um entrevistado,

[...] para mim é fundamental o parecer do agrônomo da cooperativa na hora de comprar os produtos, a gente confia nos agrônomos da cooperativa, já tem uma historia, tem a credibilidade e a confiança também, a gente sabe que eles não vão indicar um produto que não vai funcionar direito.

Esta relação valorosa que se estabelece entre cooperativa e cooperado é primordial para o atendimento das reais necessidades do associado e para a manutenção de relações duradouras entre as partes, relações estas que são um dos principais objetivos do marketing.

A cooperativa criou junto aos seus associados a cultura de busca pelo serviço, ou seja, o associado acostumou-se a ir até a cooperativa buscar informação, trocar ideias com os técnicos e encontrar possíveis soluções para seus problemas. Apenas $30 \%$ dos entrevistados concordaram de alguma forma que deixam de comprar insumos da cooperativa pela ausência do departamento técnico da Cotrisel na sua propriedade.

Apesar de parecer contraditório, ao discutir a afirmativa, muitos associados relataram que não compram todos os insumos na cooperativa, muitas vezes por a cooperativa não possuir determinado produto e em outras ocasiões são levados à concorrência por motivos diversos. O que mais chama atenção é o número de vezes que foi citado a presença dos concorrentes nas propriedades e nas comunidades e a disponibilidade destes de entregar os insumos nas lavouras. Sendo assim, um dos fatores que leva os associados a comprar insumos fora da cooperativa é a presença dos concorrentes nas propriedades, pois segundo um dos entrevistados, "os concorrentes estão sempre passando lá por casa, quando dá o acaso de estar precisando de alguma coisa naquele momento eu acabo comprando, porque aí eu não preciso vim para cidade".

Os resultados somados aos comentários indicam que a cooperativa necessita de adequações para obter maior eficiência em sua área de atuação, podendo desta forma atender as necessidades dos cooperados.

Ao se analisar o item praça sob a perspectiva dos associados, quando fornecedores da cooperativa, na primeira proposição objetivou-se analisar se a localização da cooperativa influencia na decisão de depositar a produção na cooperativa, assim 63,33\% dos entrevistados concordou plena ou parcialmente que são influenciados, 3,33\% não opinaram e 33,33\% discordaram parcial ou totalmente. Para os produtores de arroz, a localização da cooperativa é adequada e não consideram relevante a influência dos concorrentes em suas decisões. Já para os produtores de soja a localização da cooperativa possui influência direta nas suas decisões de onde depositar a produção da oleaginosa, muitas vezes optando por entregar sua produção em pontos de recebimento mais próximos as suas propriedades.

Em seus comentários os associados, produtores de soja, apresentaram posicionamentos diferentes conforme o seu volume de depósitos na cooperativa. Os cooperados que depositam maior parte da produção na Cotrisel consideram a localização adequada e atribuem pouca importância a esta questão.

Para um dos entrevistados,

[...] é mais longe levar a produção na cooperativa, e ainda às vezes tem fila, demora para descarregar, e para gente que depende de caminhão de fora para transportar a produção é mais complicado ainda, porque o caminhoneiro quer toca rápido, quer agilidade, o tempo 
que ele fica para ele está perdendo dinheiro e acaba nos pressionando a levar onde é mais perto e mais vantajoso para ele também.

Embora alguns cooperados demonstrem certa insatisfação com a localização e pontos de recebimento da cooperativa, $86,67 \%$ dos entrevistados concorda que a área de atuação e abrangência da cooperativa e seus pontos de recebimento são satisfatórios e suficientes. quando questionados se deixam de depositar sua produção na cooperativa por ter concorrentes instalados mais próximos à sua propriedade, $76,67 \%$ relataram que não deixam de depositar na cooperativa por este motivo.

Para um entrevistado,

[...] eu deposito praticamente toda minha produção de arroz e soja na Cotrisel, tem uma unidade de recebimento da concorrência bem pertinho da minha casa, mas prefiro trazer tudo para Cotrisel, faz anos que a gente trabalha com a cooperativa e sempre que eu precisei foi ela que me ajudou, para mim é melhor aqui.

Os associados que possuem um bom relacionamento com a cooperativa ignoram de certa forma a presença dos concorrentes mais próximos às suas propriedades, diferente da postura dos associados que se relacionam menos com a cooperativa e não são tão assíduos em suas negociações.

Os cooperados não percebem a presença do departamento técnico da cooperativa como fator relevante na decisão de depositar a produção na cooperativa. A relação de influência existente entre departamento técnico e cooperado se dá, de forma mais incisiva nas negociações de insumos agrícolas.

As proposições sobre promoção foram analisadas de forma geral, sem distinção entre o duplo papel exercido pelos cooperados, sendo clientes e fornecedores ao mesmo tempo. Logo, $70 \%$ dos entrevistados consideram eficientes as formas de divulgação utilizadas pela cooperativa na mídia, sendo que os principais canais utilizados pela cooperativa são os jornais e programas de rádio.

Contudo, foi possível observar que os cooperados se ressentem de um volume maior de informação, eles relatam que as informações deveriam ser mais abrangentes, que a Cotrisel deveria otimizar a utilização das mídias para informar melhor os cooperados sobe as vantagens que a cooperativa oferece, divulgar de forma mais ampla as linhas de insumos que a cooperativa oferece, as oportunidades de negocio que surgem e que poucos associados tomam conhecimento.

A utilização das mídias é de suma importância para que os cooperados possam ter acesso às informações sobre a cooperativa. No caso específico da Cotrisel em Restinga-Sêca, o horário em que a rádio local possui mais audiência é o dos avisos da Cotrisel, os produtores criaram o costume de parar às onze horas da manhã para ouvir o informativo, onde são passadas as cotações dos produtos agrícolas, a previsão do tempo e os avisos gerais.

Observou-se durante a entrevista que os associados esperam por outras informações além das tradicionais.

Para um dos entrevistados,

[...] a cooperativa tinha que aproveitar melhor esse horário da rádio, têm que chamar o associado para dentro da cooperativa, falar das oportunidades de negócio, avisar quando tem alguma condição diferenciada para a compra dos insumos, fala das vantagens que a cooperativa oferece.

Para outro entrevistado,

[...] eu só fico sabendo alguma coisa sobre a cooperativa quando venho aqui, no rádio vocês falam pouca coisa, tem que divulgar melhor a cooperativa, a gente que tá lá fora 
tem que ficar sabendo das coisas também, as vezes a gente fica um bom tempo sem vim para cidade, e aí não se sabe de nada da cooperativa, só os preços e a previsão do tempo mesmo.

Dos entrevistados, apenas $10 \%$ concordaram plenamente que a cooperativa transmite com eficiência todas as vantagens que oferece aos cooperados, 63,33\% concordaram parcialmente, $6,67 \%$ não opinaram e $20 \%$ discordaram parcial ou totalmente.

Ao serem questionados se consideram o site da cooperativa um bom canal de comunicação e promoção, $50 \%$ dos entrevistados concordaram plena ou parcialmente, 46,67\% não opinaram e 3,33\% discordaram parcialmente. Os associados que não opinaram ou que discordaram parcialmente, são indivíduos que não acessam a internet e por isso não utilizam o site ou até mesmo não têm interesse em utiliza-lo devido às questões culturais e de conhecimentos específicos.

Com relação aos dias de campo, seminários, e palestras técnicas, como pontos de relevância e influência na decisão de compra dos insumos ou de comercialização da produção na cooperativa, mais de $80 \%$ dos associados consideram estes fatores importantes e reconhecem sua influência em seus negócios, tanto que, quando os concorrentes realizam os mesmos tipos de ações promocionais, 43,33\% dos entrevistados assume que deixa de negociar com a cooperativa devido a estas ações.

$\mathrm{Na}$ afirmativa que analisou se a cooperativa apresenta de forma satisfatória suas vantagens competitivas, $56,67 \%$ dos entrevistados concordaram plena ou parcialmente, $6,67 \%$ não opinaram e $36,67 \%$ discordaram parcial ou totalmente. Observou-se que os cooperados possuem dificuldade em perceber os diferenciais da cooperativa, tanto por falta informação, por falta de divulgação por parte da cooperativa e tanto por parte de interesse do associado em analisar de forma sistemática tudo o que a cooperativa oferece. Os fatores estruturais foram os que obtiveram o maior número de citações, bem como valores intrínsecos existentes as relações entre cooperativa e cooperado.

O processo de investigação permitiu ainda constatar que a cooperativa identifica claramente as necessidades dos associados, mas questões ligadas a sua estrutura administrativa tornam o processo de adequação mais demorado. A morosidade dos processos acaba por deixar cooperativa, em algumas circunstancias um passo a traz dos concorrentes. Os cooperados consideram que esta demora significa que o empenho da cooperativa não é proporcional a relevância das suas necessidades.

Conforme exposto, os resultados da análise demonstraram que a Cotrisel apresenta pontos ineficientes em seu mix de marketing, conforme as perspectivas dos associados. Demonstraram também que a cooperativa poderia explorar de forma mais ampla e abrangente a força e a credibilidade da marca Cotrisel. Tais resultados evidenciam um grande dilema a ser discutido: o quão importante pode ser para a cooperativa a modernização da sua gestão, adoção de praticas empresariais mais agressivas, a implementação da diferenciação entre os associados procurando atender as necessidades especificas de cada um.

Embora os interesses dos cooperados sejam convergentes, a cooperativa corre o risco de que a heterogeneidade do seu quadro social apresenta-se como fonte de divergências e conflitos de interesses entre grupos de cooperados. Neste sentido podem residir às dificuldades em atender as necessidades das individualidades.

Devido a solidez da Cotrisel, o constante crescimento que vem apresentando nos últimos anos e o destaque no cooperativismo agropecuário, seria incoerente afirmar que a cooperativa é ineficiente em seu mix de marketing. Embora a Cotrisel não possua um departamento de marketing estabelecido, os resultados expostos evidenciam que a cooperativa possui muito mais pontos eficientes do que ineficientes, e esta constatação corrobora com posição ocupada pela cooperativa. 
Finalmente, o estudo possibilitou identificar que a cooperativa ainda possui uma grande fatia de mercado a ser conquistado ou reconquistado, mas para tanto serão necessárias adequações que lhe tornem mais competitiva e maior visibilidade no cenário local, em sua área de abrangência e atuação, ou seja, nas comunidades em que se propôs atuar.

\section{CONCLUSÃO}

Ao analisar a eficiência do marketing praticado pela Cotrisel, conclui-se que a cooperativa é eficiente, embora possua uma boa perspectiva de crescimento ao passo que crie alternativas e adequações que lhe possibilitem ser mais competitiva.

Verificou-se a existência de pontos em que a cooperativa apresentou um índice de eficiência pouco satisfatório. Os fatores identificados foram: os preços pagos pela soja e as quebras técnicas praticadas pela cooperativa; a falta de presença da cooperativa nas propriedades; a entrega de insumos nas lavouras e os preços dos insumos agrícolas e, finalmente, a pouca exploração da força e da credibilidade da marca Cotrisel.

Para sobreviver no mercado, as cooperativas agropecuárias têm enfrentado dificuldades para se adaptar à crescente competição. Para serem eficientes e competitivas deverão repensar os seus modelos de gestão, rever seus princípios doutrinários e estatutos, definir critérios de eficiência e fidelidade no relacionamento com seus cooperados, proporcionando maior eficácia econômica e social.

Assim, a Cotrisel precisa encontrar o equilíbrio entre as necessidades dos cooperados e o que pode ser feito para que estas necessidades possam ser atendidas satisfatoriamente de modo que esta relação seja vantajosa para as partes, gerando o crescimento econômico e social mutuo. Para tanto o marketing apresenta-se como uma ferramenta importante para o planejamento e obtenção de resultados que servirão como base para que a relação entre cooperados e cooperativa seja constante e duradoura.

Devido à abrangência do marketing, o estudo evidenciou algumas lacunas, as quais poderão servir para futuros estudos, tais como o marketing como ferramenta para fidelização dos cooperados, bem como a discussão da definição de fidelidade nas relações negociais atuais, a modernização da gestão e a heterogeneidade do quadro social como possível fonte de conflito de interesses entre grupos na cooperativa.

Como pesquisador, o presente estudo de caso proporcionou um significante crescimento intelectual e cultural. A oportunidade de analisar individualidades, suas percepções e perspectivas, onde se evidencia o quão amplo e ao mesmo tempo restrito é o universo do ser humano, o quão individualista pode ser um individuo cooperativista. Estes elementos acabam nos levando a reflexão sobre importância do respeito às diferenças e o quanto as trocas de experiências podem ser enriquecedoras, estando o homem em constante processo de aprendizagem.

Assim, acredita-se que um estudo dessa natureza possa contribuir para o fortalecimento da pesquisa acadêmica nessa área, bem como poderá auxiliar a Cotrisel a analisar suas ações e ainda, auxiliar para futuras pesquisas direcionadas ao marketing em cooperativas agropecuárias.

\section{REFERÊNCIAS}

ANTONIALLI, L. M. Influência da mudança de gestão nas estratégias de uma cooperativa agropecuária.

Revista de Administração Contemporânea. v.4, n.1, Curitiba, jan/abr 2000. Disponível em: $\langle$ http://www.scielo.br/scielo.php?pid=S1415-65552000000100008\&script=sci_arttext $>$. Acesso em 01 $\operatorname{dez} 2014$. 
BELL, J. Projeto de pesquisa: guia para pesquisadores iniciantes em educação, saúde e ciências sociais. Porto Alegre: Artmed, 2008.

BERTOLIN, R. V. Assimetria de Informação e Confiança em Interações Cooperativas. Revista de Administração Contemporânea, Curitiba, v.12, n.1, 2008.

BERTO, R. M. V. S., NAKANO, D. N. A. Produção científica nos anais do encontro nacional de engenharia de produção: um levantamento de métodos e tipos de pesquisa. Revista Produção, v. 9, n. 2, 2000 .

BOESCHE, L.; MAFIOLETTI, R. L. Evolução e indicadores do cooperativismo Brasileiro e Paranaense. Revista Negócios e Tecnologia da Informação, v. 1, n. 1, 2006. Curitiba/PR: 2005. Disponível em: $<$ http://publica.fesppr.br/index.php/rnti/article/view/v1n1ART6/90>. Acesso em: 25 jun. 2014.

BONNEMAIZON, A.; COVA, B.; LOUYOUT, M. C. Relationship marketing in 2015: a Delphi approach. European Management Journal, v. 25, n. 1, 2007.

CAMPOMAR, M. C. Do uso de "estudo de caso" em pesquisas para dissertações e teses em administração. Revista de Administração, v. 26, n. 3, 1991. Disponível em:

<http://www.pessoal.utfpr.edu.br/luizpepplow/disciplinas/metodologia/O\%20uso\%20de\%20estudos\%20d e\%20caso.pdf $>$. Acesso em: 24 jun. 2014.

CHURCHILL, G. A.; PETER, P. Marketing, criando valor para os clientes. 2. ed. São Paulo: Saraiva, 2000.

COBRA, M. Administração de marketing no Brasil. São Paulo: Cobra Editora de Marketing, 2003.

DIAS, S. R. Gestão de marketing. São Paulo: Saraiva, 2003

FARIA, R. L de. Gestão de marketing nas cooperativas rurais. Revista Complexus. Salto/SP. v.1, n. 2, 2010. Disponível em: <http://engenho.info/revista/ed02/dartigos/8-Artigop107-120.pdf>. Acesso em: 24 jun. 2014.

FLICK, U. Introdução à pesquisa qualitativa. São Paulo: Artmed, 2009.

GIL, A. C. Como elaborar projetos de pesquisa. São Paulo: Atlas, 1996.

Estudo de caso. São Paulo: Atlas, 2009.

KOTLER, P. Marketing para organizações que não visam o lucro. São Paulo. Atlas. 1998.

LUNA, S. V. Planejamento de pesquisa: uma introdução. São Paulo: EDUC, 2007.

MATOS, M. A.; NINAUT, E. S. O cooperativismo frente às perspectivas econômicas: organização das cooperativas brasileiras. INFOTEC: Informativo Técnico do Sistema OCB. v. 3, n. 2, 2007.

MÖLLER, K. Theory map of business marketing: relationships and networks perspectives. Industrial Marketing Management, v. 42, n. 3, 2013.

OCB. Organização das Cooperativas do Brasil. Nascimento de uma grande ideia. Brasília 2013. Disponível em: <http://www.ocb.org.br/site/cooperativismo/historia.asp〉. Acesso em: 28 nov. 2014.

OLIVEIRA, A. C. S.; SILVA, L. A. P.; SILVA, A. A importância das cooperativas e seu papel na sociedade. Revista Organizações e Sociedade, n. 4, v.3, 2014.

OLIVEIRA, T. C. O desenvolvimento das cooperativas de trabalho no Brasil. Perspectiva Econômica. São Leopoldo. n.12, n.38, 1982. 
OLIVEIRA, D. de P. R. Manual de gestão das cooperativas: uma abordagem prática. $2^{\mathrm{a}}$ Ed. São Paulo. Atlas. 2003.

Planejamento estratégico: conceitos, metodologia e praticas. $7^{\text {a }}$ Ed. São Paulo. Atlas. 2005.

PREFEITURA MUNICIPAL DE RESTINGA-SECA. Disponível em: <

https://www.restingaseca.rs.gov.br/index.html>. Acesso em 03/11/2013.

PINHO, D. B. O pensamento cooperativo e o cooperativismo brasileiro. $18^{a}$ Ed. São Paulo: CNPq, 1982.

REIS, G. C.et al. Marketing para cooperativa: Camda Cooperativa Agrícola Mista. São Paulo, 2012. Disponível em: <http://www.unisalesiano/edu.br/biblioteca/monografias/46221.pdf〉. Acesso em: 04/03/2016.

REVISTA AMANHÃ. 500 maiores do Sul. Disponível em: <http://www.amanha.com.br>. Acesso em: 24 jan. 2014.

SILVERMAN, D. Interpretação de dados qualitativos. Porto Alegre: Artmed, 2009.

SCHERER, F. L.et al. Análise do ambiente de marketing: em estudo aplicado em uma cooperativa do setor de agronegócios da região centro-oeste do Rio Grande do Sul. Revista de Gestão e Organizações Cooperativas, v.2, n.4, 2015.

THUSEK, C. N. L. Cultura da cooperação: uma abordagem psicossocial em uma cooperativa de trabalho. Revista Gestão \& Tecnologia, v. 6, n. 1, 2006. Disponível em:

<http://www.unipel.edu.br/periodicos/index.php/get/article/viewFile/170/165>. Acesso em: 31 out. 2013.

TRIVIÑOS, A. N. S. Introdução à pesquisa em ciências sociais: a pesquisa qualitativa em educação. São Paulo: Atlas, 1987.

ZYLBERSZTAJN, D. Organização de cooperativas: desafios e tendências. Revista de Administração da USP. São Paulo v. 29, n. 3, 1994. Disponível em:

〈http://www.fundacaofia.com.br/pensa/pdf/papers/Zylbersztajn\%20Cooperativas\%201994.pdf>. Acesso em: 25 jun. de 2011.

Quatro estratégias fundamentais para cooperativas agrícolas. In: XIV Seminário de Política Econômica: Cooperativismo e agronegócio. Universidade Federal de Viçosa, out. 2002. Disponível em: 〈http://www.ead.fea.usp.br/wpapers/>. Acesso em 01 dez. 2013. 